\title{
Analysis the influence of a mesoscale cold eddy on underwater sound propagation in the east of Luzon Strait
}

\author{
Hai-Lin Ruan, Yan-Ming Yang, Hong-Tao Wen, Xin Xie, Fu-Qiang Niu \\ Third Institute of Oceanography, State Oceanic Administrator \\ Daxue Road 178 \\ Xiamen, Fujian, P. R. China \\ ruanhailin@tio.org.cn, 86-592-2195519
}

\begin{abstract}
$^{1}$
Based on the data of Argo float, satellite altimeter merged data, and HYCOM model output, we analyzed the temporal-spatial variations of a mesoscale cold eddy in the east of Luzon Strait, and used FOR3D model to simulate the effects of this mesoscale cold eddy on sound propagation, Calculated out the transmission loss(TL) with or without the cold eddy. Result show that the presence of cold eddy led to significant variation of sound propagation. Typically, the distances of convergence zones were narrowed several kilometers, and the gain of convergence zones were inhibited about $2 \mathrm{~dB}$.
\end{abstract}

Key words: Sound propagation, Mesoscale eddy, Argo, HYCOM, FOR3D

\section{Introduction}

The 3D structures of eddies can be hardly determined, but are generally acquired by constructing ideal eddy structure models [1-4], the effects of eddies on sound propagation are analyzed together with sound propagation models. Also a few experiments have been conducted to investigate the effects of mesoscale eddies on sound propagation [5-7]. In all, the existing studies about the effects of mesoscale eddies on sound propagation are mainly based on construction of eddy structure models, but the accuracy of models should be further validated. However, field investigation into the effects of mesoscale eddies on sound propagation is very difficult.

Along with the development of remote sensing, Argo float and other novel observation techniques, the high-resolution ocean model has been gradually improved, which facilitates the extraction of 3D structures from mesoscale eddies [8]. In this study, together with the data of remote sensing, Argo float, and ocean model, we used FOR3D sound propagation model to analyze the effects of cold eddy on sound propagation.

\section{Temporal-spatial variation of Mesoscale Cold Eddy}

Fig.1, the No.5900056 Argo float generally moved anticlockwise from the 6th cycle to the 25th cycle observation periods, which was characteristic of cyclonic eddies. Since the

This work was supported in part by the National Nature Science Foundation of China under Grant 41606116, in part by the Natural Science Foundation of Fujian Province of China under Grant 2016J01019 and the Scientific Research Foundation of Third Institute of Oceanography, SOA(NO.2014018) . data of altimeters can validate the cyclonic cold eddy during this period in the study area. Fig.2 shows the sea level anomaly (SLA) distribution, sea surface geostrophic current, and position of No.5900056 argo float during the mature period of cold eddy (broken lines in Fig.1). The cold eddy became mature in 13 June 2004 , its center was located at $124.5^{\circ} \mathrm{E}$ and $22.5^{\circ} \mathrm{N}$, its radius was about $100 \mathrm{~km}$, and the mature period lasted until 7 July 2004.

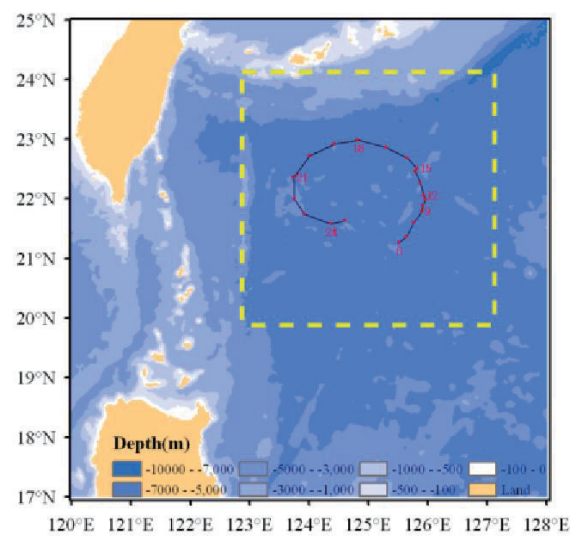

Fig.1 The terrain and the trajectories of 5900056 Argo float

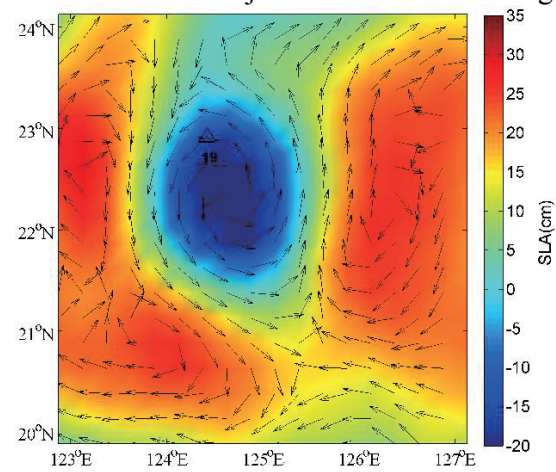

Fig.2 The distribution of SLA under the cold eddy on 2004-06-25( $\triangle: 5900056$ Argo float $)$

\section{Effects of cold eddy on 3D sound propagation}

The sound propagation under cold eddy environment was simulated using FOR3D sound propagation forecast model [9]. 
The mode parameters were as follows: source depth $=100 \mathrm{~m}$, source frequency $=100 \mathrm{~Hz}$, seawater density $=1024 \mathrm{~kg} / \mathrm{m} 3$, seabed consisting of sedimentary layer and basement; sedimentary layer thickness $=20 \mathrm{~m}$; sound speed rising linearly from 1550 to $1580 \mathrm{~m} / \mathrm{s}$, density $=1.6 \times 103 \mathrm{~kg} / \mathrm{m} 3$, coefficient of absorption $=0.1 \mathrm{~dB} / \lambda$; basement sound speed $=1546 \mathrm{~m} / \mathrm{s}$, density $=1.8 \times 103 \mathrm{~kg} / \mathrm{m} 3$, absorption coefficient $=0$; horizontal step length $=2 \mathrm{~m}$; vertical separation $=5 \mathrm{~m}$, interval of directional angle $=3^{\circ}\left(0^{\circ}\right.$ northwards $)$, and receiver depth $=40-200 \mathrm{~m}$. Then the effects of cold eddy on 3D sound propagation were simulated when the sound source was located at the center or outside of the cold eddy.

\section{A. Sound source at the center of cold eddy}

When the sound source was at O1 the center of the cold eddy, the sound signals propagated from $\mathrm{O} 1$ to outwards, the horizontal transmission distance was $150 \mathrm{~km}$, and the terrain within the $0-360^{\circ}$ range is showed in Fig. 4 .

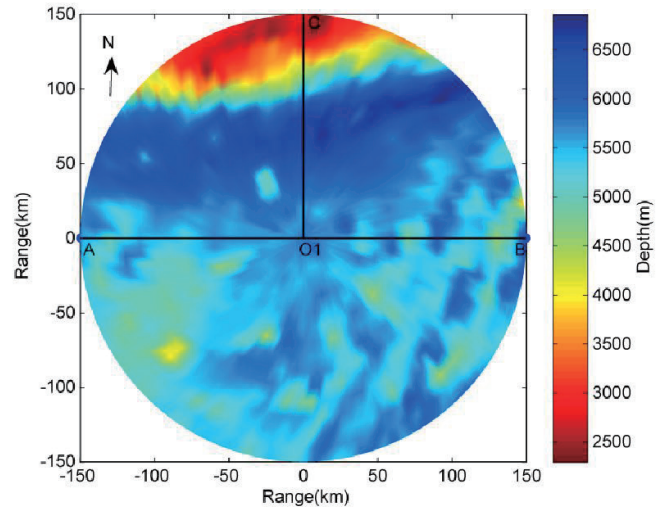

Fig.4 Terrain of sound propagation distance $150 \mathrm{~km}$

The temperature and salinity sections on line A-O1-B of 25 June 2004 were extracted from the HYCOM model outputs, and the sound speed section was calculated using the Chen\&Millero sound speed empirical algorithm[8]. With A as the referenced sound speed profile, calculated the anomaly of A-O1-B sound speed profiles under the cold eddy, the sound speed anomaly distributions of A-O1-B section(Fig.5). The largest effect of the cold eddy on sound speed appeared at 400 $\mathrm{m}$ deep in the center of the cold eddy, and the variation was up to $-16 \mathrm{~m} / \mathrm{s}$.

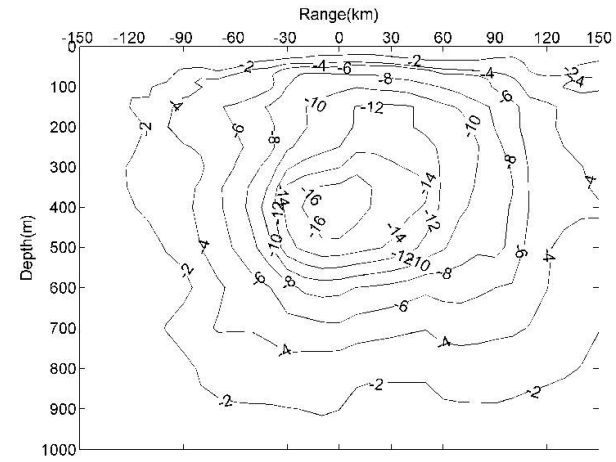

Fig. 5 sound speed anomaly of A-O1-B section (b)



Fig.6 The difference of TL between the presence and absence of cold eddy (receiver depth $=100 \mathrm{~m}$ )

The sound TLs with and without the eddy were simulated using the FOR3D model. Fig.6 shows the difference of between the presence and absence of cold eddy. The presence of cold eddy led to significant variation of sound propagation. The difference in some zones were up to $20 \mathrm{~dB}$, and the areas with large difference were located at the first and second convergence zones, and the shallow water areas in the north. The positions of the convergence zones all moved towards to the sound source, and their distances was narrowed down by $5-6 \mathrm{~km}$.

Fig. 7 shows the TL curves of O1B in Fig. 3 without and with the presence of cold eddy. Clearly, the first and second convergence zones moved about 3 and $6 \mathrm{~km}$ toward to the sound source, and the gains of the convergence zones were slightly inhibited.

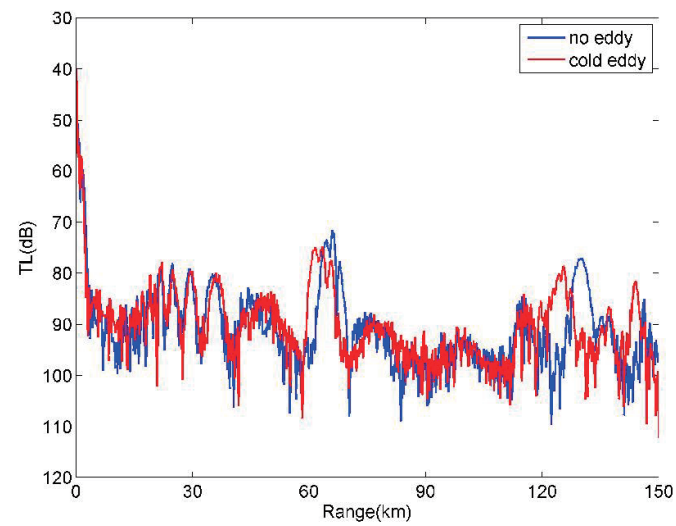

Fig.7 Sound TL curves of O1B (receiver depth $=100 \mathrm{~m}$ )

\section{B. Sound source located outside cold eddy}

When the sound source was located at $\mathrm{O} 2$ outside of the cold eddy, the SLA distribution around $\mathrm{O} 2$ is showed in Fig. 8. The extent of broken line shows the TL simulated zone, and the horizontal propagation distance was $240 \mathrm{~km}$. The sound propagation at the left passed through a cold eddy, center of which was about $120 \mathrm{~km}$ from O2. The 3D temperature and salt structure of the zone were also extracted from the HYCOM model output. The TL without or with cold eddy was simulated 
using an FOR3D model.

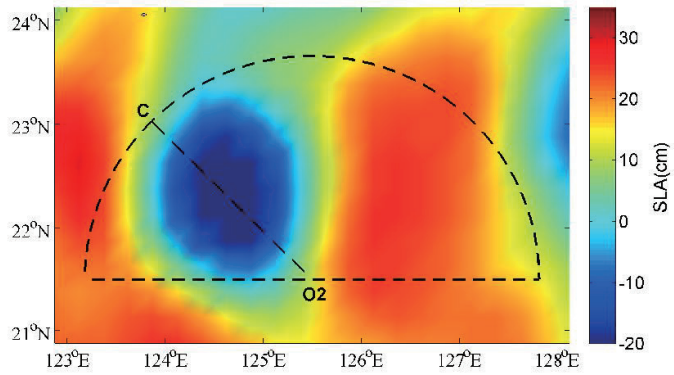

Fig. 8 SLA distribution when the sound source was located outside of the cold eddy

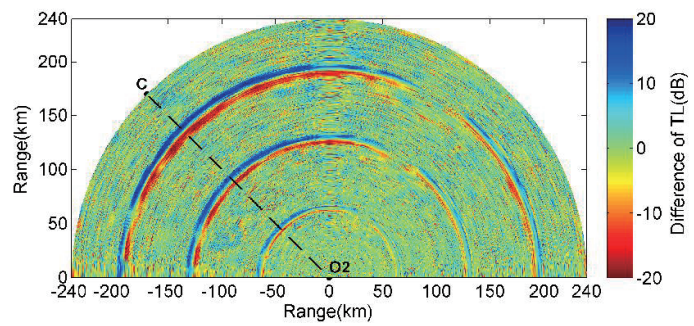

Fig. 9 The difference of TL between the presence and absence of cold eddy and without eddy (receiver depth $=100 \mathrm{~m}$ ).

Fig. 9 shows the difference of TL between the presence and absence of cold eddy. The difference at the left side of the cold eddy is significantly larger than the no-eddy zone at the right side, and the maximum difference appears at the three convergence zones and is up to $20 \mathrm{~dB}$.

Fig. 10 shows the O2C TL curves, where the blue and red curves indicate the absence and presence of the cold eddy, respectively. The three convergence zones are very characteristic. The cold eddy made the three convergence zones all migrate to the sound source by about 2,5 and $7 \mathrm{~km}$, respectively, and the TL of the cold eddy to the center of the convergence zones decreased by about $2 \mathrm{~dB}$.

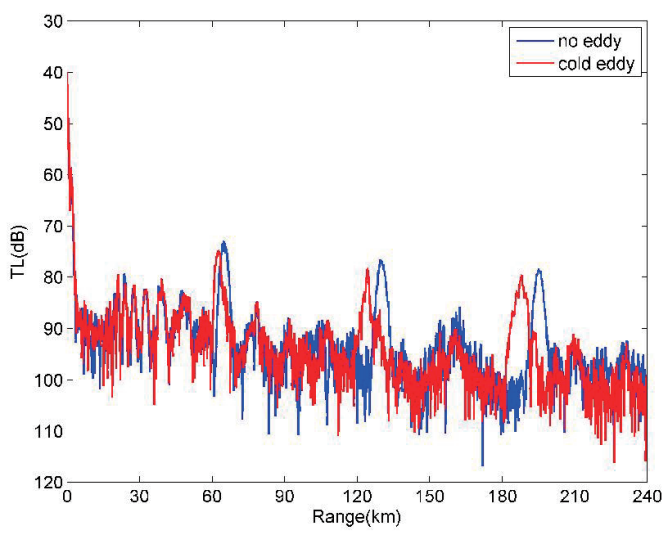

Fig.10 Sound TL curves when source was outside cold eddy $(\mathrm{O} 2 \mathrm{C}$, receiver depth $=100 \mathrm{~m})$
Based on the data of Argo float, satellite altimeter merged data, and HYCOM model output, we analyzed the time-space changes of a mesoscale cold eddy in the east of Luzon Strait, and used FOR3D model to simulate the effects of this mesoscale cold eddy on sound propagation.

(1) The mesoscale cold eddy caught by the Argo float was in radius of $\sim 100 \mathrm{~km}$ when it stabilized, and the affected depth on temperature-salt was up to $800 \mathrm{~m}$. The Sound speed variation due to the cold eddy maximized to $-16 \mathrm{~m} / \mathrm{s}$ at water depth of $400 \mathrm{~m}$.

(2) When the $100 \mathrm{~Hz}$ sound source was located at the center of the cold eddy, the presence of the cold eddy largely affected the sound propagation. The propagation loss differences in some parts reached $20 \mathrm{~dB}$. The first and second convergence zones were located at 3 and $6 \mathrm{~km}$ away from the sound source, and the gains in the convergence zones declined.

(3) When the $100 \mathrm{~Hz}$ sound source was outside of the cold eddy, the three convergence zones also migrated by 2, 5 and 7 $\mathrm{km}$, respectively, to the sound source, and the gains at the center of the convergence zone declined by about $2 \mathrm{~dB}$.

\section{References}

[1] J. G. Watson, W. L. Siegmann, M. J. Jacobson. Deep-ocean dynamics for environmental acoustics models $[\mathrm{J}]$. The Journal of the Acoustical Society of America, 1976, 60(2): 355-364..

[2] R. F. Henrick, W. L.Siegmann, M. J. Jacobson. General analysis of ocean eddy effects for sound transmission applications [J]. The Journal of the Acoustical Society of America, 1977, 62(4): 860-870.

[3] R. N. Baer. Calculations of sound propagation through an eddy[J]. The Journal of the Acoustical Society of America, 1980, 67(4): 1180-1185.

[4] Y. J. Jian, J. Zhang, Q. S. Liu, et al. Effect of mesoscale eddies on underwater sound propagation[J]. Applied Acoustics, 2009, 70(3): 432-440.

[5] Nysen P A, Scully - Power P, Browning D G. Sound propagation through an East Australian Current eddy[J]. The Journal of the Acoustical Society of America, 1978, 63(5): 1381-1388.

[6] X. Zhang, J. X. Zhang, Y. G. Zhang, et al.. Effect of acoustic propagation in convergence zone under a warm eddy environment in the western South China Sea [J]. Ocean Engineering, 2011, 29(2): 83-91.

[7] V. A. Akulichev, L. K. Bugaeva, Y. N. Morgunov, et al. Influence of mesoscale eddies and frontal zones on sound propagation at the Northwest Pacific Ocean[J]. The Journal of the Acoustical Society of America, 2012, 131(4): 3354-3354.

[8] Z. Zhang, W. Wang, B. Qiu. Oceanic mass transport by mesoscaleeddies[J]. Science, 2014, 345(6194): 322-324.

[9] P. Fofonoff, R. C. Millard. Algorithms for computation of fundamental properties of seawater[R]. Paris: UNESCO Technical Papers in Marine Science, 1983, 44:5-20.

[10] X. T. Lu, L. Zhang. Review of Sound Propagation Modeling in Underwater Warfare Environment[J]. Ocean Technology, 2010, 29(4): 48-53.

\section{Conclusions}


Recent Developments on Information and

Communication Technology (ICT) Engineering- Meen, Yang \& Zhao ISBN: 978-981-14-2136-5 